\title{
THE UNIT OF CONSTRUCTION + THE MULTIPLE POINT OF VIEW = THE EVOLUTION OF FORM
}

Carl Smith

Learning Technology Research Institute

London Metropolitan University

carl.smith@londonmet.ac.uk

http://www.rlo-cetl.ac.uk/developers/smith

\begin{abstract}
Architecture, Archaeology, Art History and Design are just some of the disciplines where dynamic access to their units of construction is essential. Distinct forms of knowledge can be detected at different scales of analysis. In order to discern the processes and distinct construction methodologies present in these subjects (to see across as opposed to from a fixed point of view) new interfaces are required for increasing the range of the dialogue. Mixed reality techniques, 'the internet of things', ambient intelligence and the 'clickable' world are beginning to offer a whole new range of critical methods for the internal and external analysis of objects, texts, designs and ideas. Audiences are now able to investigate networks of disparate objects in ways their original individual authors fundamentally could not. Whereas printed media provide us with a single, static version of such knowledge, these new techniques provide us with dynamic content which allow us to trace changes over time and space.
\end{abstract}

\section{INTRODUCTION}

The ability to bi-directionally interrogate existing architecture (using QR codes, 3D mapping, GPS etc.) whilst dissecting multiple points of view onto that architecture (in the form of an online database of virtual reconstructions) is intended to accelerate the re-contextualization and re-organization of ideas. Such techniques were adopted by ancient orators in order to remember and organize speeches using a combination of visual memory and association [1]. The capacity for users to have this 'active hand' in the construction of their own 'take on things' via visualizations which can be dynamically generated and transformed on the fly, in situ, and 'saved' will be shown to be a vital element contributing to effective learning outcomes.

An archaeological learning environment (figure 1) will be explored to question whether more can be learnt about a specific building or style of architecture if that building or style is itself treated as a network. The process of data-mining hierarchies of evidence (intellectual transparency) in the quest for constituent parts, key narratives and evolutions of form will be explored in depth (figure 2). 


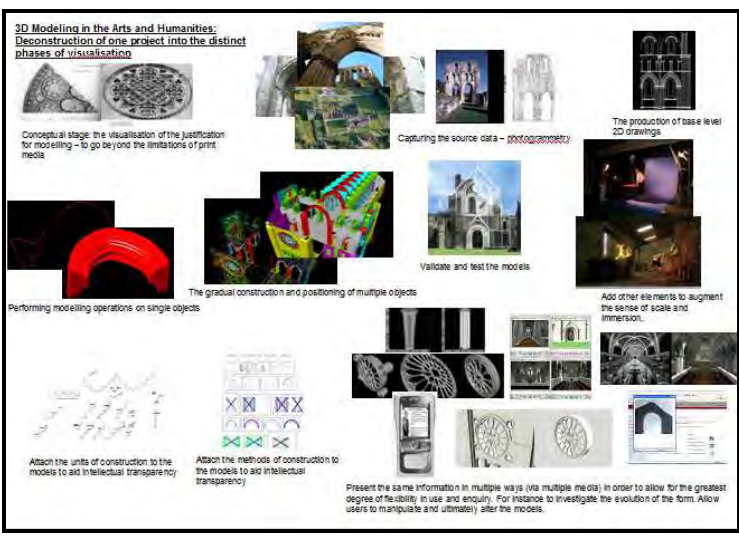

Figure 1.

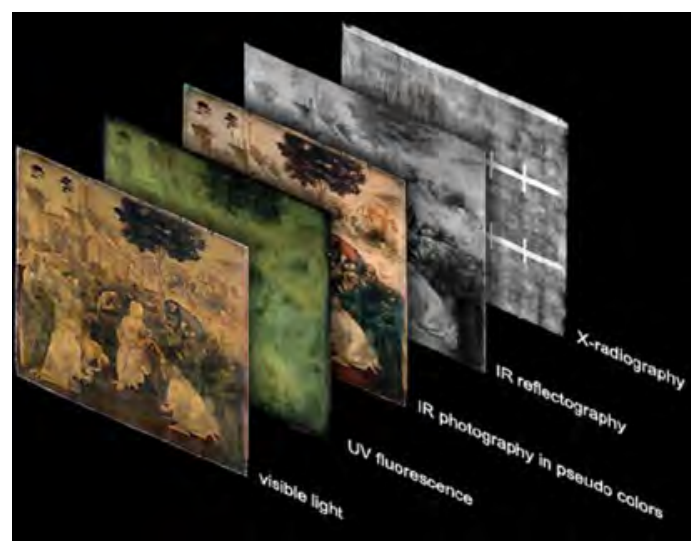

Figure 2.

\section{OBJECTIVES}

In archaeological surveying the capacity of print to supply the entire set of reasoning that leads from the design of the $2 \mathrm{D}$ plans to the final $3 \mathrm{D}$ form is usually restricted by the authors prescribed forms of analysis. The opportunity to query the data, at the junctures of its development which are specific to the individual researchers needs is often lost or made extremely difficult.

At present most digital versions of such archaeological 'learning environments' also place an overwhelming emphasis on the final presentation of the product. As a result, the developmental stages are rarely made available to researchers. In order to contribute to current academic debate it is essential that access to the source material and supporting evidence for every reconstruction is established and maintained. The whole range of information that might be encountered in the process of the object's lifecycle must be communicated as an integral part of the product. Then the total range of knowledge contained within the resource can be utilised, allowing many diverse and wide-ranging opinions to be tested and unified for further analysis. "Archaeologists are able to distribute full excavation data, in addition to their interpretations, allowing other researchers to re-analyse the material to confirm conclusions or to draw new ones. Research queries can be answered in a more complete manner, generating interesting details and stimulating the researcher to refine the question(s) being asked, occasionally leading to completely new avenues of enquiry" [2].

The functional meaning of any site is more accurately translated through an actual understanding of the structured navigation of the space. "Each vantage point, each mode of organisation will create a new structure. And each new structure will enable you to see a different manner of meaning, acting as a new method of classification from which the whole can be grasped and understood'[3].

\section{DEVELOPMENT PROCESS}

A wide variety of visualization and mixed reality procedures were used to create the content for the web and mobile based application. The first phase of development involved recording the source data (the physical remains from five archaeological sites) 
in a number of ways. These ranged from the process of photogrammetry (a visualization technique where geometric coordinates are determined by measurements made in two or more photographic images taken from different positions) to locating and piecing together fragments of masonry in conceptual and physical space.

The photogrammetric process resulted in hard-copy 2D prints that were scanned and scaled into an industry standard modelling package (AutoCad). They were then overdrawn to provide a base set of reconstruction drawings (elevations and ground plans). The next phase of development involved using these 2D CAD drawings to create $3 \mathrm{D}$ solids using a number of specific modelling procedures. The most common of these is the extrusion (figure 3).
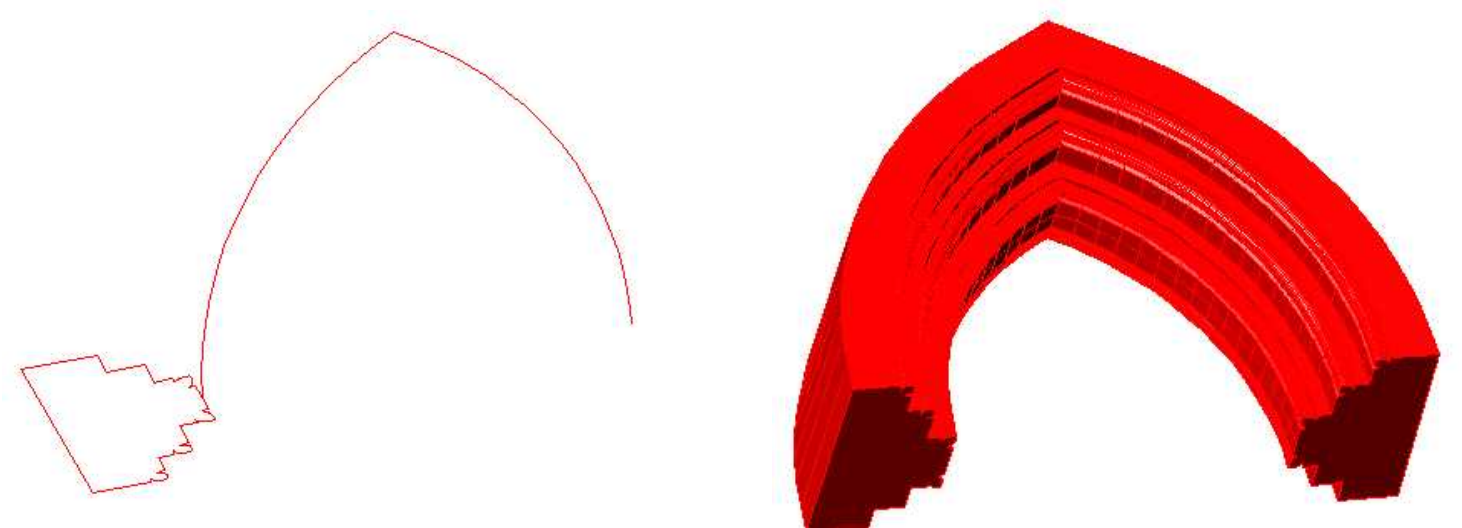

Figure 3. Visualization Technique - The Extrusion

The extrusion process begins with the profile (architectural moulding), namely a cross section through the object (as shown to the left of figure 3) and the path, namely the outline of the object, (as shown to the right of figure 3) being extracted from the ground plans and elevations. These codes of construction are then added to the database. The profile is then extruded along the path to form the main structure of the object (see figure 6). This object itself is then added to the database.

These extrusions were used throughout the model and each time an extrusion was carried out it was documented and that documentation was tagged (metadata) to the object itself. Gradually single objects were carefully placed into position (figures 4 and 5) according to the ground plan and elevation survey data. 


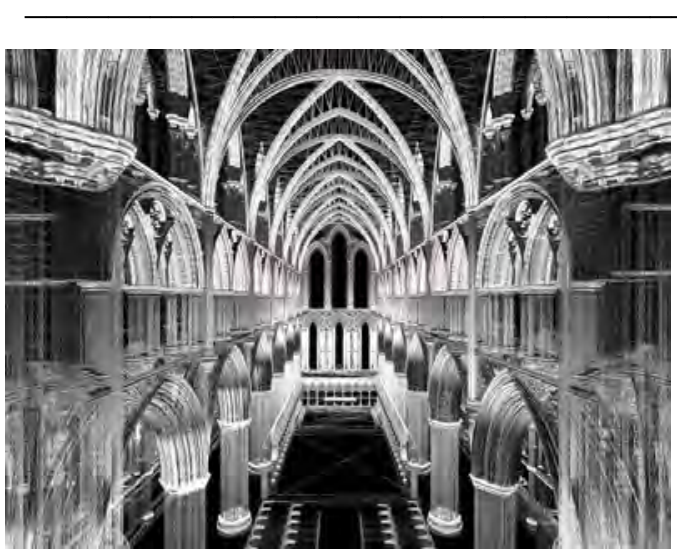

Figure 4.

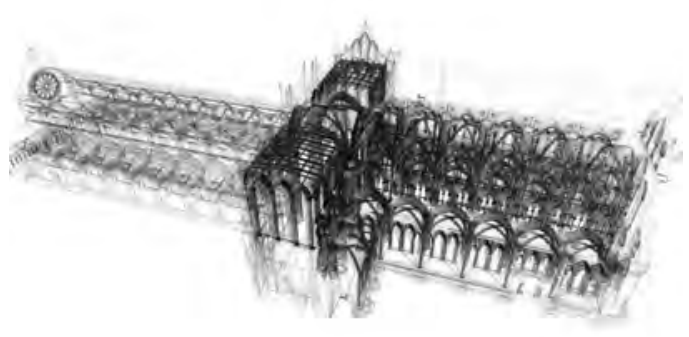

Figure 5.

There were a number of other visualization techniques used to give a sense of scale, and to augment the sense of immersion within the models. The main techniques involved the compositing of video (of people) via green-screens into the models (figure 6 ) and camera matching (figure 7).

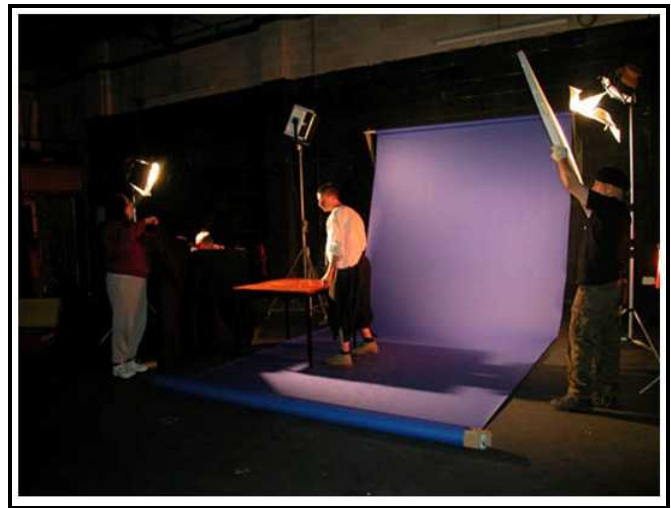

Figure 6.

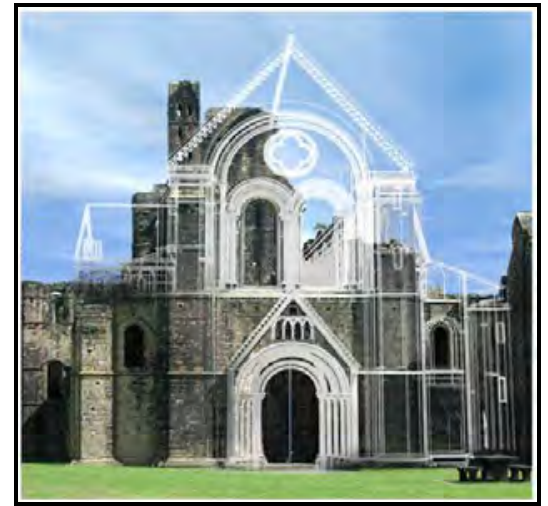

Figure 7.

\section{USER GENERATED VISUALIZATION}

Inheritance and the innate structural hierarchy of the reconstructions are utilised to allow the visual desegregation of a design into its original elements. Users can drill down through the final presentation of the model (the front end to the whole data set) into all the component objects and any architectural element within the model to automatically load any linked information which that element may have attached. This includes: Textual information including architectural data and archaeological data, the supporting evidence for that element of the reconstruction, analysis of influences and the original 3D CAD files, the original 2D CAD drawings, QTVR panoramas, images, sounds, movies etc.

These objects can then be extracted from their hierarchical structures, manipulated, measured and reconfigured according to the users unique research query. For example each abbey can be represented as a collection of their constituent architectural mouldings (figure 8). A significant amount of the architectural style is embedded in the 
structure of these mouldings along with invaluable information about their origins. Via the application the user is able to search and transform these 2D mouldings into their final 3D forms in order to examine how (for instance) the Gothic style (figure 9) of architecture compares and potentially relates to the Romanesque style. Questions relating to the levels of certainty, the actual construction process carried out by the master masons, the evolution of the structures at multiple levels, and their related influences could also be tackled.

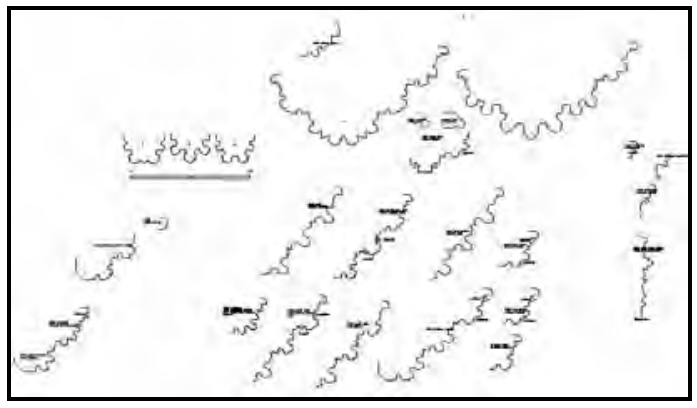

Figure 8. The Units of Construction

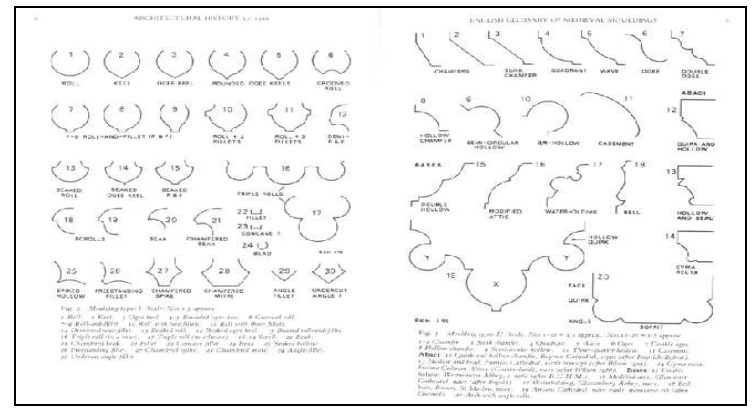

Figure 9. The Gothic Style

Another aspect of the project was to attach the methods of construction (of both the 3D models and the physical structures) to the models themselves (figure 7) so they could also be interrogated and potentially reused (best practise).

\section{ATTACHING INFORMATION TO SPACE}

In order to allow for the greatest degree of flexibility in use and enquiry the outputs of the project can be visualized in multiple ways (via multiple media) these include via the web and in situ on site via mobile phones. GPS is used to locate the user and present the appropriate reconstruction and complete access to the online database of materials.

The emerging discipline of mobile learning is promoting the practise of attaching information to space. The result is an ever increasing liquidising of the world where everything becomes mediated. All form is fused with information and through parallel developments (including pattern recognition) the world itself is becoming an interface.

The question is what impact will the use and development of this 'interface' have on knowledge formation and what are the new construction methodologies at work in the transformation of information into knowledge?

Kim Veltman in his essay The New Book of Nature explores scenarios where it is the geometry of the objects themselves that is used as a means of identification (for further investigation) via pattern recognition: "Cell phone cameras which were traditionally passive instruments to record images from the natural world, are transformed into active search engines for exploring and discovering knowledge.... the natural world, which was traditionally simply something "out there" now becomes a new kind of interface for the exploration of knowledge" [4].

In this world of smart objects it will be possible to approach any object (using photography in this instance) and unlock everything you could ever want to know about that object (its meaning, history, content, context, close relations) is made available. 
EVA 2009 London Conference 6-8 July

Carl Smith

Information is folded into the space of the object and the organisation of that information is structured by the space.

Photosynth [5] is also an interesting development as it generates intuitively navigable three-dimensional models of photos. Pattern recognition is used to compare portions of images to create points, which are then compared to convert the image into a model.

The 'Internet of Things' [6] involves a number of technologies including RFID, NFC (near field communication), and sensor networks which enable the internet to reach out into the real world of physical objects. If objects become smart in the sense that they all carry identifying devices knowledge formation will undergo a further transformation.

This means that each architectural element outlined in the project above can be tagged in both virtual and physical space. Eventually the user will be able to: "follow the tradition of each architectural element, be it a portal, a niche or a vault; to witness its interplay with corresponding forms as spatial motifs in paintings and treatises; and in some cases see how this interplay leads to an evolution in the complexity of a form" [7].

\section{CONCLUSION}

The path to creativity is paved with open access to the process: "The way to creativity is the path of the not yet and its reality can be very important even if there is no physical product.... The world of design is not just about doing and making "things". The majority of designs and plans are never built.... The challenge is not just to see what we (can) know today, but to see how our ways of knowing have changed, grown and evolved over the centuries" [8].

\section{References}

[1] YATES, Frances. The art of memory. Chicago : University of Chicago Press, 1966.

[2] ROSS, Seamus. Changing trains at Wigan : digital preservation and the future of scholarship. April 1998. http://www.leeds.ac.uk/cedars/OTHER/SRoss.htm

[3] WURMAN, Richard Saul. Information anxiety. New York : Doubleday, 1989

[4] VELTMAN, Kim H. Opening keynote : The new book of nature. In : eARCOM 07. Sistemi informativi per l'Architettura Convegno Internazional. Con il

Patrocinio di UNESCO. Ministero dei Beni Culturali, CIPA, Regione Marche, Ancona-Portonovo Hotel La Fonte, 17-18-19 Maggio 2007.

[5] http://www.photosynth.net

[6] WALDNER, Jean-Baptiste. Inventer l'ordinateur du XXIeme siècle. London : Hermes Science, 2007. pp.254.

[7] VELTMAN, Kim H. A databank on perspective : the concept of knowledge packages. 1988. http://www.sumscorp.com/articles/art9.htm

[8] VELTMAN, Kim H. Opening keynote : The new book of nature. In : eARCOM 07. Sistemi informativi per l'Architettura Convegno Internazional. Con il Patrocinio di UNESCO. Ministero dei Beni Culturali, CIPA, Regione Marche, Ancona-Portonovo Hotel La Fonte, 17-18-19 Maggio 2007 